Review

\title{
Social memories in rodents: Methods, mechanisms and modulation by stress
}

\author{
Michael A. van der Kooij, Carmen Sandi* \\ Laboratory of Behavioral Genetics, Brain Mind Institute, Ecole Polytechnique Federale de Lausanne (EPFL), Station 19, CH-1015, Lausanne, Switzerland
}

\section{A R T I C L E I N F O}

\section{Article history:}

Received 18 July 2011

Received in revised form 20 October 2011

Accepted 27 October 2011

\section{Keywords:}

Social recognition

Social memory

Social transmission of food preference

Social hierarchy

Oxytocin

Vasopressin

Stress

Glucocorticoids

\begin{abstract}
A B S T R A C T
Intact social memory forms the basis of meaningful interactions between individuals. Many factors can modulate the quality of social memory, and these have been studied in detail in rodents. Social memory, however, cannot be considered a single entity. The term social memory reflects different processes, such as social recognition of a novel conspecific individual and social learning (or 'learning from others'). This review summarizes the findings obtained with behavioral paradigms that were developed for the study of memory formation by social recognition and social learning. In particular, we focus on studies that include tests for social habituation/discrimination paradigms, tests for memory of a previously established social hierarchy and the social transmission of the food preference test. The role of individual differences and the main neurobiological mechanisms (i.e., the brain regions and neurochemical systems involved) that have been implicated in each of these types of social-related memories are reviewed. In addition, we address the key modulatory influence of stress on the formation of these types of memories; discussing the contribution of central (corticotropin-releasing factor, CRF) and peripheral (glucocorticoids) stress systems and their interactions with the social neuropeptide systems. Overall, we present here a general overview of the current state of a thriving research area within the field of social neuroscience.
\end{abstract}

(c) 2011 Elsevier Ltd. All rights reserved.

\section{Contents}

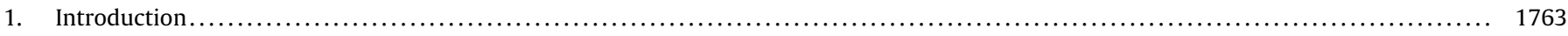

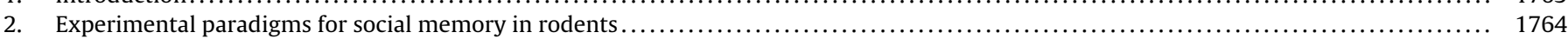

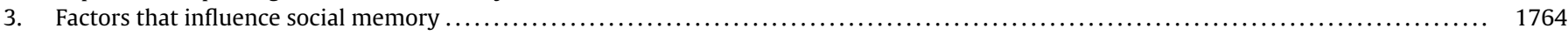

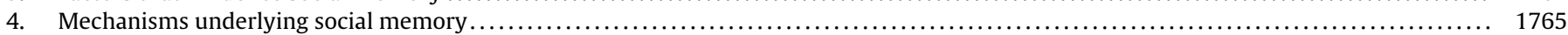

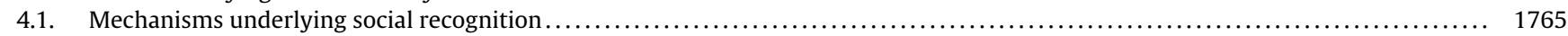

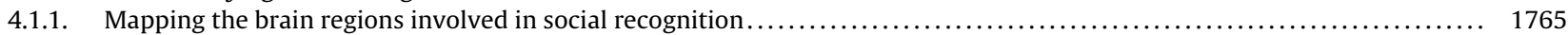

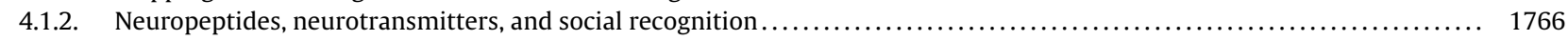

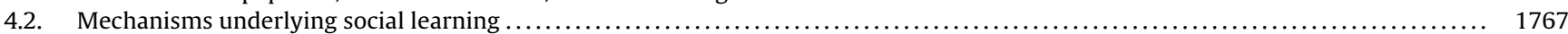

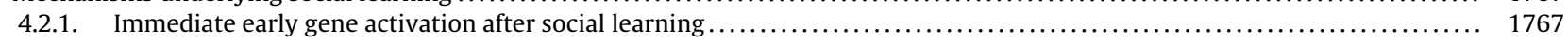

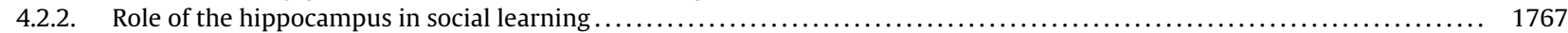

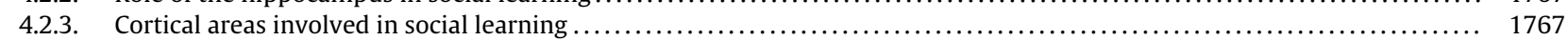

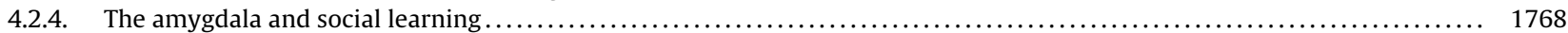

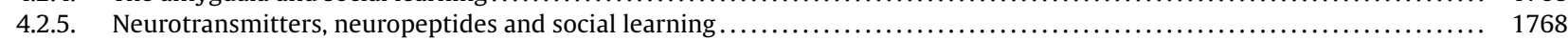

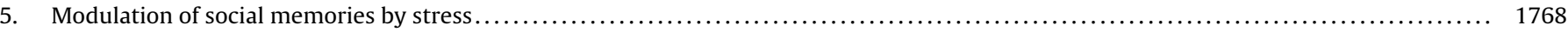

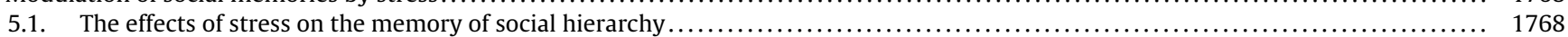

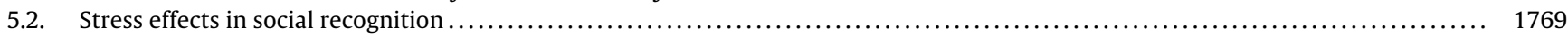

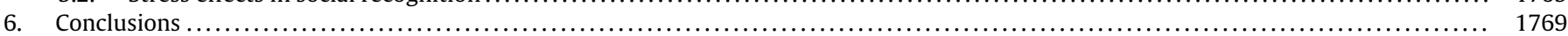

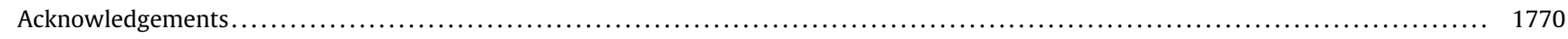

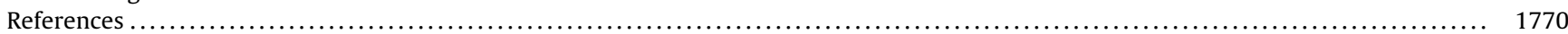

* Corresponding author. Tel.: +4121693 9534; fax: +41216939636.
E-mail address: carmen.sandi@epfl.ch (C. Sandi).

149-7634/\$ - see front matter @ 2011 Elsevier Ltd. All rights reserved. doi:10.1016/j.neubiorev.2011.10.006

\section{Introduction}

In socially behaving species, particularly mammals, a precise memory for individual conspecifics is pivotal for engaging in meaningful relationships and mounting appropriate behavioral responses based on previous encounters. The term social memory 
may include a variety of conditions. A prominent line of research investigates the social memories related to the storage of information about the qualities attributed to a specific individual (such as those linked to his or her individual signature, social status, or gender), which allows the identification of such qualities upon a subsequent encounter within a relevant time window. To a large extent, this review deals with the behavioral characteristics and neurobiology of this type of social memory. We focus on the social recognition of unfamiliar conspecifics (generally a juvenile or a female) and a recently established paradigm for assessing the memory of social hierarchy.

In addition, the phenomenon defined as 'social learning', which refers to the situations in which individuals learn from others in their social group, is also discussed. This learning is especially relevant for acquiring skills that are too difficult or time consuming for each individual to learn on its own (Shettleworth, 1998). Therefore, it is essentially different from the type of processing involved in social memories related to an individual's characteristics.

Social neuroscience is a field of emerging interest. Comprehensive reviews of both social recognition (Popik and van Ree, 1998; Bielsky and Young, 2004; Winslow and Insel, 2004) and social learning (Choleris et al., 2009) can be found in the literature. The current article summarizes the key findings obtained with the social recognition and social learning paradigms, including the factors that modulate the formation and expression of these memories and the underlying neurobiological mechanisms. Finally, we present recent work investigating the impact of stress on the formation of social memories.

\section{Experimental paradigms for social memory in rodents}

Social recognition is assessed in laboratory rodents using tests that represent different variants of a basic scheme that measures familiarity recognition. The basic principle relies on the usual propensity of rodents to investigate an unfamiliar conspecific more thoroughly than a familiar one. A recognition index is obtained by comparing the duration of the investigation for a conspecific (typically a juvenile or an ovariectomized (OVX) female) during the initial encounter to that of the second encounter with the same animal (Winslow, 2003).

The most widely used variant is the habituation/dishabituation paradigm (Thor and Hollaway, 1982), in which the experimental animal (generally an adult male) is first exposed to an unfamiliar subject. After removal of the stimulus animal and subsequent reintroduction, recognition memory is indicated by a reduction in the investigation time. In some studies, this phase is followed by the later presentation of a new conspecific, which typically stimulates social investigation. Despite its popularity, this variant presents some difficulties in data interpretation because the requirement for repeated testing may affect the motivation for social investigation (Choleris et al., 2009).

The other major variant of this social recognition test is the social discrimination paradigm (Engelmann et al., 1995, 2011). The social discrimination paradigm shares the initial exposure to an unfamiliar conspecific with the habituation/dishabituation paradigm but differs in the subsequent phase. In this case, both a familiar and a novel conspecific are simultaneously presented. In some cases, the two stimulus animals are left to freely move about the cage, whereas in other studies, they are confined within wired cups, which is frequently the case when a three-chambered apparatus is used (Silverman et al., 2010). The social discrimination paradigm has proven to be more sensitive for measuring social recognition than the habituation/dishabituation test (Choleris et al., 2009), and in particular, the variant with the three-chambered apparatus facilitates scoring with video-tracking systems.
Although these exploratory tests based on familiarity are by far the most popular tests employed to assess individual recognition in laboratory rodents, animals can also identify each other based on their respective status in their mutual social hierarchy. Cordero and Sandi (2007) showed that in unfamiliar male rats, a memory for social rank is observed when the test is performed 2 days, but not 1 week, after the first encounter. In this study, the rats were originally matched for intrinsic features (such as body weight, anxiety traits and former social status in the home cage) and interacted to compete for territory and food. This finding indicates that rats are capable of forming a memory of the acquired social hierarchy. Further experiments have suggested that it is the subordinate individual in particular that retains the memory (Timmer and Sandi, 2010).

For the phenomenon known as 'social learning' or 'learning from others', the social transmission of food preference (STFP) paradigm (Galef and Wigmore, 1983), an ethologically meaningful test of olfactory memory, has been the most extensively studied in rodents. The STFP paradigm can be employed using both rats (Galef et al., 1988) and mice (Valsecchi and Galef, 1989). In the STFP task, one animal (the 'observer') interacts with a conspecific (the 'demonstrator') that ate food with a specific flavor prior to the encounter. The 'observer' is subsequently presented with the choice of eating different, novel-flavored foods (normally 2 foods are provided, one of which was previously eaten by the 'demonstrator'). The preference for the food with the specific flavor that had been previously eaten by the 'demonstrator' indicates the presence of the memory in the 'observer' animals (Wrenn, 2004). Socially significant cues have been shown to be required for this transmission of food preference; the demonstrator may be anesthetized or sick but not dead (Galef and Wigmore, 1983; Galef, 1985). In addition, exposure to food-powdered cotton alone does not lead to a food preference (Galef et al., 1988; Valsecchi and Galef, 1989) nor does exposure to food odor alone or to a conspecific that did not previously eat the flavored food (Choleris et al., 2011).

\section{Factors that influence social memory}

As with nearly any animal behavior, there are important individual differences when the nature or properties of social memories are evaluated. Social memory performance depends on various factors, including the species, sex, age, and emotional status of the animal during the investigation.

The strength of memory in the social recognition paradigm has been shown to depend greatly on the species under investigation. The memory of mice is far superior to that of rats; recognition often wanes after 30-60 min in rats but can last for days in mice (Letty et al., 1997; Engelmann and Landgraf, 1994; Engelmann, 2009; Kogan et al., 2000). This finding is at odds with findings about other types of memory, such as spatial memory for hidden food rewards as assessed in the modified holeboard task, in which rats clearly outperform mice (van der Kooij et al., 2010a, 2010b). In addition, mice from 3 different strains displayed comparable intact STFP performance but differed markedly in other types of learning (Holmes et al., 2002). Thus, social memory performance is probably independent of other types of memory. A recent study (Noack et al., 2010) suggested that differences in olfaction between rats and mice might account for the species-specific differences in the social preference task. Thus, although the number of c-Fos-positive cells after exposure to the volatile scent of a juvenile was robustly upregulated in the accessory olfactory bulb (OB) and the main $\mathrm{OB}$ in mice, the same procedure in rats only modestly increased the number of c-Fos-positive cells and only in the accessory OB. Importantly, memory in the STFP task was shown to last for much longer than in the standard social recognition tasks in both rats and mice (Clark et al., 2002; Galef and Whiskin, 2003; Wrenn, 2004). 
Gender may also play a role in social recognition. A recent study showed that although the total investigation time of a conspecific juvenile was lower in female than in male Long-Evans rats, young female rats displayed stronger social recognition than males. Although this gender-dependent effect was not related to the estrous cycle (Markham and Juraska, 2007), other studies have shown that female knockout mice lacking estrogen receptors (ER) $\alpha$ and $\beta$ demonstrated impaired social recognition (Choleris et al., 2003). In agreement with these findings, estrogen replacement in ovariectomized mice was reported to be beneficial for social recognition (Tang et al., 2005). A more recent study identified the medial amygdala (MeA) as a site of action for the effects of estrogen administration on social recognition (Spiteri et al., 2010). Interestingly, castration of male rats results in enhanced social recognition, supposedly by diminishing arginine vasopressin (AVP) function (Bluthé and Dantzer, 1992). Of note, a role for AVP in social recognition has been established (Sekiguchi et al., 1991; Landgraf et al., 1998; Ferguson et al., 2002; Bielsky and Young, 2004; see Section 4.1.2.1). The effect of estrogens is also noted in STFP performance. Females in the pro- and diestrus phases of the estrous cycle showed enhanced STFP performance compared to estrus and OVX females (Clipperton et al., 2008). In addition, OVX females treated with an ER $\alpha$-selective agonist failed to learn STFP, whereas administration of an ER $\beta$-selective agonist prolonged STFP memory. Thus, these findings indicate differential roles for ER $\alpha$ and ER $\beta$ in social memory (Clipperton et al., 2008).

Aging is generally accompanied by the deterioration of social recognition in both rats and mice (Terranova et al., 1994). For example, old (24-month-old) Wistar rats typically demonstrate reduced social recognition in juvenile compared to young (3-month-old) rats (Prediger et al., 2006). Similarly, memory retention in the STFP test with test delays exceeding $24 \mathrm{~h}$ was impaired in old (32-month-old) rats compared to young (3-month-old) subjects (Countryman and Gold, 2007). Interestingly, the memory impairments in the STFP test in aged rats were associated with decreased pCREB, notably in the ventral hippocampus (see also Section 4.2.1) (Countryman and Gold, 2007).

In fact, the age of the 'observer' may also determine whether a STFP will develop at all; a simple exposure to an anesthetized 'demonstrator' was sufficient to induce STFP in young rats (21 days of age) but not older rat pups (Galef and Kennett, 1987). Some studies have investigated the impact of the circadian cycle on social memory. Intracerebroventricular (ICV) infusion of melatonin or histamine-both of which are important modulators of the circadian rhythm-in rats facilitated social recognition (Prast et al., 1996; Argyriou et al., 1998). However, the relevance of this variable is unclear because disruption of the circadian rhythm was not found to affect social memory in rats (Reijmers et al., 2001a).

In this section, we have highlighted some of the factors identified as pivotal for influencing the formation of social memories. However, the list is most likely not limited to those factors mentioned above.

\section{Mechanisms underlying social memory}

Immediate early gene activation, pharmacological interventions and lesion studies have underscored the involvement of specific brain regions in social recognition and social learning. Frequently, the magnitude of expression of the immediate early gene c-Fos is considered to be a marker for brain region-specific activation because this gene is rapidly transcribed in response to neuronal firing. The nature of memory in social recognition and social learning differs (see Section 2); therefore, it is logical to expect that the brain structures responsible also differ. Possible mechanisms for social recognition and social learning are therefore discussed separately below. First, we will discuss the specific brain regions involved and then focus on AVP and oxytocin (OT). This emphasis on neuropeptides notwithstanding, a number of neurotransmitter systems have also been implicated in social memory.

\subsection{Mechanisms underlying social recognition}

\subsubsection{Mapping the brain regions involved in social recognition}

Successful memory trace retrieval upon a second encounter in the social preference test is initially dependent on intact acquisition. Evaluation of the pattern of cerebral activation (as measured by immediate early gene activation) after an initial social encounter has been performed to reveal the brain regions involved in the acquisition phase. Studies performed in male mice exposed to either an OVX female mouse (Ferguson et al., 2001; Samuelsen and Meredith, 2011) or a juvenile (Richter et al., 2005; Engelmann, 2009) showed overlapping c-Fos activation patterns in a number of brain regions, including the MeA, the medial preoptic area and the piriform cortex, whereas the number of c-Fos-positive cells in hippocampal areas was unaltered. Lesion studies in rats tend to confirm a lack of hippocampal involvement in social recognition memory (Bannerman et al., 2001, 2002; Squires et al., 2006). In contrast, c-Fos activation is clearly increased in the hippocampus of mice and rats after tasks that rely on spatial navigation (Bertaina and Destrade, 1995; Vann et al., 2000; Guzowski et al., 2001; Shires and Aggleton, 2008). Therefore, the underlying mechanisms of social recognition memory and spatial memory are likely different.

Strikingly, hippocampal lesions in mice did impair social recognition memory for a juvenile $30 \mathrm{~min}$ after the first exposure without affecting immediate social recognition (Kogan et al., 2000). The discrepancy between the findings on c-Fos activation in the hippocampus of mice after the social recognition test and the effect of hippocampal lesions challenge the causal interpretation of data from immediate early gene activation in the context of memory formation. In addition, it is likely that specific brain regions are only temporarily involved in acquisition, consolidation and retrieval encoding, and this may explain the findings by Kogan et al. (2000). In this respect, in mice, it was found that two stages of protein synthesis were important for social recognition memory, a short (starting immediately after training and lasting for $3 \mathrm{~h}$ ) and a long (starting $6 \mathrm{~h}$ after acquisition and lasting for $12 \mathrm{~h}$ ) stage (Richter et al., 2005; Wanisch et al., 2008).

Furthermore, depending on whether subjects were exposed to either an OVX female or a juvenile, the brain regions in which immediate early gene activation was found differed. The olfactory bulb (OB; both the accessory ( $\mathrm{aOB}$ ) and the main ( $\mathrm{mOB}$ ) regions) was clearly implicated in mice after exposure to a juvenile (Richter et al., 2005; Engelmann, 2009) but not after exposure to a female (Ferguson et al., 2001). Importantly, the timing between the first social exposure and testing was similar in all studies, suggesting that differences in the pattern of brain activation are indeed related to the different nature of the stimuli.

Interestingly, similar regions might be involved during the acquisition and retrieval of social recognition memory. This is suggested by a study in which c-Fos activity after the first and second encounters with the juvenile was compared in mice (Engelmann, 2009). Renewed c-Fos activation was found in the same brain regions that were involved in the first exposure $(\mathrm{MeA}, \mathrm{aOB}, \mathrm{mOB}$, medial preoptic area and piriform cortex) after re-exposure to another juvenile ( $6 \mathrm{~h}$ after initial exposure). Importantly, c-Fos activation linked to the first exposure had been normalized (as evaluated $7 \mathrm{~h}$ after first exposure) before the animals were challenged for the second time.

A few studies have also explored the impact of lesioning specific areas within the frontal lobes, given the important role of this 
region in the regulation of emotions in human patients. In one study, the aim was to dissociate the roles of the anterior cingulate cortex (ACC) and the orbitofrontal cortex by performing specific lesions in rats in these subregions and testing their effects on social memory. Lesions of the ACC, but not the orbitofrontal cortex, were found to impair the social recognition of a juvenile, an effect that was not found to be secondary to reduced social investigation or impaired odor detection (Rudebeck et al., 2007).

\subsubsection{Neuropeptides, neurotransmitters, and social recognition}

The study of the neurochemistry of social memories has largely concentrated on the 'social neuropeptides', OT and AVP, which will be the focus of this section. OT and AVP are closely related neuropeptides that are produced in the paraventricular nucleus and supraoptic nucleus of the hypothalamus as well as in extra-hypothalamic sites (see Castel and Morris, 1988). They are currently acknowledged for their major involvement in social behavior in both rodents (Bielsky and Young, 2004; Ross and Young, 2009) and humans (Meyer-Lindenberg, 2008).

4.1.2.1. Vasopressin and social recognition. The crucial role of the vasopressinergic system in social behavior was elegantly shown in studies conducted in voles. Prairie voles are monogamous, exhibit biparental care and have considerable social contact. The montane vole shows an opposite phenotype; these animals are promiscuous, have little social contact and only maternal care is observed (Young et al., 1999; Lim et al., 2004; Young and Wang, 2004). It was found that cerebral AVP (mediating its actions through AVP1aR and AVP1bR, the AVP1a and AVP1b receptors, respectively) was responsible for these differences in their behavioral phenotypes (Young et al., 1998; Donaldson and Young, 2008).

In rats and mice, the vasopressinergic system plays an important role in social memory (Bluthé et al., 1993; Reijmers et al., 2001b; Bielsky et al., 2005). Brattleboro rats, for example, lack AVP production in the hypothalamus and do not recognize a juvenile conspecific encountered 30 min earlier. In turn, administration of AVP into the lateral septum restores social recognition in the Brattleboro rat without affecting social exploration per se (Engelmann and Landgraf, 1994; Feifel et al., 2009). The lateral septum is a brain structure that was found to be central to the mediation of social recognition. Insertion of the AVP1aR prairie vole gene into the rat lateral septum or overexpression of AVP1aR in the lateral septum improved social recognition (Landgraf et al., 2003; Bielsky et al., 2005). Conversely, social recognition was reduced by the local administration of specific AVP1aR antagonists (Landgraf et al., 2003; Bielsky et al., 2005). Using genetic approaches, AVP1 aR KO mice were found to have reduced anxiety-like behavior and impaired social interaction (Bielsky et al., 2004; Egashira et al., 2007), including impaired social recognition of an OVX female conspecific (Bielsky et al., 2004). Wersinger et al. (2007) reported that social recognition was intact in AVP1aR KO mice and was accompanied by a disrupted habituation/dishabituation to odor and reduced main olfactory functions (Wersinger et al., 2007), which is in contrast to the data reported by Bielsky et al. (2004). It was suggested that the different ratios of hybrid backgrounds used (ratios of C57Bl/6J vs. 129 mice) may explain these discrepancies in behavioral performance (Wersinger et al., 2007). AVP1bR is expressed in the brain at lower levels than AVP1aR. It also shows a more limited distribution, although, importantly, it is expressed in regions that are crucial for social behaviors (including the OB, medial preoptic area and amygdala) (Hernando et al., 2001). Accordingly, AVP1bR KO animals show reduced interest in a conspecific when given the choice to explore a juvenile vs. an empty compartment. In fact, AVP1bR KO mice did not show a significant social preference during the test, indicating a lack of social interest
(DeVito et al., 2009). In the same study, social recognition of a juvenile conspecific was not detected in AVP1bR KO mice.

Studies manipulating AVP1bR have mainly focused on its role in the OB. AVP infused into the OB enhanced social recognition in rats (Dluzen et al., 1998), and the local infusion of an AVP1R antagonist, small interfering RNA targeting of AVP1aR mRNA or the specific destruction of vasopressinergic cells in the OB impaired social recognition in rats (Tobin et al., 2010). Critically, the disruption of the vasopressinergic system in the OB did not affect object recognition or olfactory functions (Tobin et al., 2010). In agreement with these findings, object recognition was also intact in AVP1bR KO mice (DeVito et al., 2009). This suggests that AVP is important for the social component of social recognition because perturbations of this system do not appear to affect object recognition. Apart from the involvement of the lateral septum and $O B$ in AVP-mediated social recognition, the MeA may also mediate social recognition. Maternal memory (signified by the latency to foster pups) was impaired after infusion of an AVP1a antagonist into the MeA (Nephew and Bridges, 2008).

4.1.2.2. Oxytocin and social recognition. Oxytocin is structurally and functionally related to AVP and plays a very important role in social memory (Bielsky and Young, 2004). ICV injections of OT facilitated social recognition of a juvenile in rats that could be blocked with an OT antagonist (Benelli et al., 1995; Dluzen et al., 1998; Samuelsen and Meredith, 2011).

The development of OT KO mice further established the major role of OT in social memory. OT KO mice from both genders showed impaired social recognition without alterations in social approach, olfactory functions or cognitive impairments (Choleris et al., 2003; Crawley et al., 2007; Ferguson et al., 2000). The social recognition deficit in OT KO mice was rescued through OT infusion (Ferguson et al., 2000, 2001). OT receptor (OTR) KO mice showed impaired social recognition (Takanayagi et al., 2005), in line with the findings obtained in OT KO mice. Moreover, mice from which the OT receptor was inactivated from postnatal days 21 to 28 onward also showed impaired social recognition (Lee et al., 2008). Importantly, in this study, loss of OTR binding was most prominent in the lateral septum, the hippocampus and ventral pallidum and significantly reduced in the $\mathrm{OB}$ and neocortex; however, it remained unchanged in the MeA.

The MeA was found to be an important site of action for OT functioning in social memory. Local infusion of OT mimicked the beneficial effects of OT on social memory that were observed after ICV infusion (Ferguson et al., 2001), whereas antisense DNA against the gene encoding the OT receptor infused into the MeA resulted in impaired social recognition (Choleris et al., 2007). The specificity of the MeA becomes clear when considering that lesions to the basolateral amygdala (BLA) did not affect the social recognition of a juvenile (Maaswinkel et al., 1996).

4.1.2.3. Neurotransmitters and social recognition. Acetylcholine has been shown to play a key role in social recognition. Systemic administration of the partial muscarinic cholinergic agonist arecoline or the antagonist scopolamine has been shown to decrease or increase social recognition, respectively (Letty et al., 1997; Millan et al., 2007; Loiseau et al., 2008). Much less is known about the specific involvement of norepinephrine (NE) and, notably, dopamine (DA) and serotonin (5-HT) in social memory. Disruption of the noradrenergic system has been shown to impair social recognition (Marino et al., 2005; Griffin and Taylor, 1995), whereas the administration of an $\alpha 2$-adrenergic antagonist (which increases NE concentrations) has been shown to improve social recognition (Griffin and Taylor, 1995). DA has also been found to facilitate the modulation of social recognition. Finally, evidence of a role for the serotonergic system has also been observed. The $5-\mathrm{HT}_{4}$ and $5-\mathrm{HT}_{6}$ 
receptors have been implicated in social recognition, with the frontal cortex playing a key role in the mediation of these effects (Letty et al., 1997; Loiseau et al., 2008).

As with other types of behavior, the neurotransmitter systems involved in social recognition do not act on their own. For example, stimulation of the D1 receptor in the frontal cortex and hippocampus or blockage of the D3 receptor in the frontal cortex was shown to stimulate local cholinergic neurotransmission and subsequent social recognition (Di Cara et al., 2007; Millan et al., 2007). Examining the interactions among the various neurotransmitter systems that are committed to social recognition is the next step required to lead to a deeper understanding of their contribution to social memory formation.

\subsection{Mechanisms underlying social learning}

\subsubsection{Immediate early gene activation after social learning}

Immediate early gene activation following the STFP task revealed brain regions involved in the acquisition, storage and retrieval of this type of memory. c-Fos activity was enhanced in the ventral hippocampus at acquisition and retrieval tested 2 days after STFP (Countryman et al., 2005). In another study, c-Fos activation was measured during retrieval testing immediately and 1,2, and 21 days after STFP acquisition in rats. Enhanced c-Fos activation after STFP retrieval was found in the orbitofrontal cortex, the anterior piriform nucleus, the lateral entorhinal cortex and the dentate gyrus of the ventral hippocampus and became more pronounced with longer intervals between the training and retrieval sessions (Ross and Eichenbaum, 2006). In contrast, in the ventral subiculum, c-Fos activation was enhanced when the retrieval occurred immediately after training, but c-Fos activation decreased with retrieval sessions at later time points.

In a more recent, comprehensive study in rats, c-Fos activation was investigated both after acquisition and after recall tests, which allowed the researchers to delineate the contribution of particular brain regions specifically to acquisition and retrieval. Positive c-Fos cells were counted either immediately after interaction with a 'demonstrator' or after a 24-h delay. In addition, c-Fos activation was also measured after a recall test at $48 \mathrm{~h}$ and after a recall test 1 week after acquisition (Smith et al., 2007). Immediately after the STFP task, enhanced c-Fos activation was found in the ventral hippocampus (CA3 and dentate gyrus), the parahippocampal cortex and the medial prefrontal cortex (prelimbic subregion). The dorsal hippocampus, the orbitofrontal cortex, the posterior parietal cortex and the amygdala (basolateral, lateral and central nuclei) were also investigated but did not show differential c-Fos expression at this time point. At $24 \mathrm{~h}$ after the first encounter, none of the investigated brain regions showed significantly increased numbers of c-Fos-positive cells, indicating that the initially enhanced c-Fos activation due to STFP acquisition was normalized before the subsequent recall test. During the recall test at $48 \mathrm{~h}$, the CA3 region of the hippocampus, the medial prefrontal cortex (pre- and infralimbic subregions) and the lateral orbital region of the orbitofrontal cortex were significantly activated. Only the orbitofrontal cortex (lateral orbital and ventral orbital parts) was activated at the 1-week recall test (Smith et al., 2007).

Some regions may show only short-lasting activation (such as the subiculum), whereas others are activated for a longer duration (orbitofrontal cortex). The challenge remains, however, to elucidate how these regions act in concert to coordinate STFP performance.

\subsubsection{Role of the hippocampus in social learning}

Early lesion studies suggested that the hippocampus plays a key role in the consolidation of STFP but not its acquisition or short-term retention (Bunsey and Eichenbaum, 1995; but see Burton et al., 2000). In more recent studies, it was shown that intact hippocampal c-Fos and CREB levels prior to STFP training were required for 14 and 3 days STFP memory, respectively, but not for short-term (immediate) STFP memory (Brightwell et al., 2005; Countryman et al., 2005). Along the same lines, cholinergic input (from the medial septum/vertical limb of the diagonal band of Broca (MS/VDB) to the hippocampus was found to be crucial for 24-h retrieval of STFP performance, whereas immediate retention was not affected (Berger-Sweeney et al., 2000). However, in another study, immediate, 24-h and 3-week post-training STFP performance were not impaired after lesions to the cholinergic input from the MS/VDB to the hippocampus. In this study, the animals were also tested for retrograde memory. The rats acquired a food preference 5 days prior to MS/VDB lesioning and were impaired when tested for STFP at 10-11 days. (Impaired STFP performance was not seen when food preference was acquired 1 day prior to lesioning.) Thus, in this study, STFP impairments appeared only when the demonstration was performed after surgery, suggesting that anterograde memory is not dependent on cholinergic neurotransmission in the hippocampus (Vale-Martínez et al., 2002). Importantly, infusion of the muscarinic cholinergic antagonist scopolamine into the ventral hippocampus immediately after social training decreased STFP performance that was tested $24 \mathrm{~h}$ later (Carballo-Márquez et al., 2009a). Together, these findings emphasize the importance of cholinergic hippocampal neurotransmission for STFP memory consolidation.

The role of the hippocampus in systems consolidation of STFP has also been tested. Performance in rats was reduced when the lesion was made 1-day, but not 21 or 30 days, post-training (Clark et al., 2002; Ross and Eichenbaum, 2006). These results indicate that an intact hippocampus is not required for recall of the STFP task following a long delay after training.

Together, the work reviewed in this section suggests that the hippocampus is important for STFP performance at intermediate retention intervals (1-14 days). The hippocampus seems to play a less important role when STFP is tested immediately after training or with very long retention intervals (3 weeks or longer). The lack of an effect of hippocampal manipulations after very short (immediate) retention intervals could indicate that selective attention is not impaired. Perhaps hippocampal activation for STFP at very long (21 days or longer) retention intervals is not required because this type of memory may be integrated by then into cortical structures that compensate for the dysfunctional hippocampus.

\subsubsection{Cortical areas involved in social learning}

Surgical removal of the frontal lobes in rats was found to impair STFP, although the impairments differed from those observed in rats exhibiting hippocampal lesions in that these impairments were only apparent when animals were given a choice between three (but not two) food odors (Winocur and Moscovitsch, 1999). In subsequent studies, the role of specific cortical regions and/or neurotransmitter systems in STFP was investigated. Lesions to cholinergic projections from the nucleus basalis magnocellularis (NBM)/substantia innominata to the neocortex impaired performance when tested immediately and $24 \mathrm{~h}$ after acquisition (Vale-Martínez et al., 2002). In conclusion, the cholinergic projections to the neocortex are likely to be pivotal in the acquisition of food preference, which is in contrast with the role of the hippocampal cholinergic afferents that play a role in memory retrieval of STFP (see Section 4.2.2).

Specific lesions to the orbitofrontal cortex did not affect STFP performance when tested $1 \mathrm{~h}, 1$ or 10 days after the initial test (Smith et al., 2010). However, when rats were injected with 192-saporin into the orbitofrontal cortex, which reduced the number of local cholinergic fibers by approximately $30 \%$, the animals showed no preference for the demonstrated food when tested 1-2 days later. Hippocampal levels of acetylcholine were shown 
to be correlated with STFP performance (Berger-Sweeney et al., 2000; Ross et al., 2005). It was not mentioned, however, whether potential attention or learning deficits or other abnormalities were caused by the lesions. Berger-Sweeney et al. (2000) noticed that food intake was considerably reduced in the lesioned animals. Therefore, ascertaining the role of the orbitofrontal cortex for social learning warrants further investigation.

Infusion of the muscarinic cholinergic antagonist scopolamine into the prelimbic cortex of rats before or during training impaired STFP performance $24 \mathrm{~h}$ after the last training session (Boix-Trelis et al., 2007; Carballo-Márquez et al., 2007). In contrast, STFP performance was not affected when scopolamine was administered $1 \mathrm{~h}$ after training, suggesting that the cholinergic system in the prelimbic cortex is likely important for the acquisition and early consolidation of the task (Carballo-Márquez et al., 2007). Although it was reported that the quality of social interaction between the 'observer' and the 'demonstrator' was not different between sham- and scopolamine-treated animals and that olfaction was intact, other non-specific effects of scopolamine on learning and/or attention cannot be excluded (for further reading, see Klinkenberg and Blokland, 2010). Follow-up studies should thus focus on whether these promising results can be reproduced using more specific interventions with less putative side effects (e.g., 192-saporin or muscarinic M1 antagonists).

\subsubsection{The amygdala and social learning}

Information in the literature regarding the role of the amygdala in STFP learning is not clear. Activation of the nucleus basalis magnocellularis (which, among other brain regions, sends cholinergic afferents to the amygdala (Wenk, 1997) facilitates STFP, suggesting involvement of the amygdala in STFP learning (Boix-Trelis et al., 2006; Vale-Martínez et al., 2002). However, lesioning the amygdala using ibotenic acid did not affect subsequent STFP performance (Burton et al., 2000).

In contrast, local infusion of the $\mathrm{GABA}_{A}$ agonist muscimol into the BLA (thereby temporarily inactivating the BLA) impaired the acquisition but not retention of STFP memory (Wang et al., 2006). Furthermore, scopolamine (a muscarinic cholinergic antagonist) injected into the BLA impaired STFP performance (tested $24 \mathrm{~h}$ after demonstration) without altering behavioral interaction or total food consumption (Carballo-Márquez et al., 2009b). Taken together, current data implicate the amygdala (at least the BLA) in STFP. The differential effects on social learning, which result from manipulations known to affect the amygdala as described above, may result from conflicting contributions of amygdala subregions and/or extra-amygdala lesion effects of ibotenic acid infusion, although this remains to be investigated.

\subsubsection{Neurotransmitters, neuropeptides and social learning}

From studies described in Sections 4.2.2-4.2.4, it is clear that the cholinergic system is crucial for intact STFP with dominant roles for this neurotransmitter system in the hippocampus, cortical areas and the (basolateral) amygdala. Although not investigated to the same extent, other neurotransmitter systems are involved in STFP as well. There is evidence of a role for the serotonergic system in STFP. More precisely, 5-HT receptor 3a KO mice of both sexes show impaired STFP, whereas the interaction time or anxiety-like behaviors did not differ from controls (Smit-Rigter et al., 2010). The NMDA receptor is yet another target for memory modulation. Rats that received the NMDA receptor antagonists CPP or MK801 showed intact STFP at $24 \mathrm{~h}$ but were impaired at $72 \mathrm{~h}$ (Roberts and Shapiro, 2002).

In agreement with the findings concerning social recognition, an early study describes the facilitation of STFP by peripheral administration of an AVP analog or OT after the encounter with the 'demonstrator' (Popik and van Ree, 1993). However, AVP and OT do not improve STFP under all circumstances. Intrahippocampal injections of AVP produced amnesic effects similar to CPP and MK801 as described above (Roberts and Shapiro, 2002). Furthermore, pretest peripheral administration of an AVP metabolite (peptide sequence 4-9) improved subsequent STFP memory at intervals when memory was poor in controls, but it impaired STFP at intervals in which controls showed normal memory (Strupp et al., 1990).

\section{Modulation of social memories by stress}

Recent work indicates that the emotional status of rats can modulate social memories (Cordero and Sandi, 2007). This phenomenon agrees with a considerable body of data showing that emotional experiences, including stress, can affect the formation of memory in a broad sense (de Kloet et al., 1999; McGaugh and Roozendaal, 2002; Joëls, 2006; Kim and Diamond, 2002; Sandi, 2004; Luksys and Sandi, 2011). To our knowledge, no information is available as to whether stress might affect an individual's capability to form memories when learning from others, although our hypothesis is that memory formation for this type of learning will also be affected by stress. The modulation of social memory formation by prior acute stress has been investigated in the social recognition task and in a recently developed paradigm to investigate memories based on social hierarchy formation. In both cases, stress was found to potentiate the formation of the memory for social hierarchy and social recognition.

\subsection{The effects of stress on the memory of social hierarchy}

The study of memory in the social hierarchy between two male rats has recently revealed a strong modulatory action of stress. In socially living animals, the establishment of dominance hierarchies provides the dominant individual with priority access to limited resources, such as water and food, space or females, and has the advantage of reducing fighting within a group, eventually minimizing energy costs. In laboratory rats that are kept together in a colony, a hierarchy usually develops within a few days and is generally stable as long as the group remains together (Blanchard et al., 1988).

A social hierarchy can also be observed after two unfamiliar rats (matched for body weight and anxiety-like behavior) are placed in a neutral cage. When two male rats are separated after the initial establishment of a social hierarchy, the same order for hierarchy can still be observed when these animals are reunited 2 days later (but not when animals are replaced 7 days after the initial encounter) (Cordero and Sandi, 2007). Interestingly, stress experienced by one of the males just before their first encounter can determine the long-term establishment of a social hierarchy by influencing both the rank achieved during the social encounter and by facilitating long-term memory of the achieved hierarchy; overall, the stressed animal becomes subordinate and retains the same status in the test 1 week after the initial encounter (Cordero and Sandi, 2007). These stress-induced, memoryenhancing effects were antagonized by the administration of the protein synthesis inhibitor anisomycin after the first encounter (Cordero and Sandi, 2007), which supports the involvement of memory consolidation mechanisms in the long-term effects of stress on social hierarchy establishment. Interestingly, the lasting effect of stress is specific in potentiating a recognition memory for "the particular individual" because (i) only exposing one of the males of the pair to stress without an immediate social interaction does not determine the social hierarchy displayed by the animals if they are confronted for the first time 1 week after stress delivery, and (ii) a submissive relationship on day 8 is not observed in 
stressed males that had their first social encounter on day 1 and were exposed 1 week afterward to an unfamiliar dominant male.

Given the role of the social neuropeptide systems OT and AVP in social behaviors and social memory formation (see Section 4.1.2) and the fact that stress has been shown to lead to OT and AVP release in different brain areas (Engelmann et al., 1999; Ebner et al., 2000; Wotjak et al., 1996, 1998; Neumann, 2007), the involvement of social neuropeptide systems in the effects of stress on the establishment of a long-term social hierarchy has recently been studied. More specifically, the role of OTR and V1aR in the MeA and lateral septum was investigated (Timmer et al., 2011). Potentiation of the social hierarchy by stress was found to be accompanied by social status- and region-specific changes in the expression of OTR gene (Otr) mRNA in the MeA $3 \mathrm{~h}$ after the social encounter. At this time point, no evidence was found for the regulation of V1aR mRNA in the MeA or lateral septum. Pharmacological experiments in which a specific OTR antagonist was infused into the MeA immediately after the acquisition of a subordinate status under basal, non-stress conditions suggested a role for this receptor in the MeA in the long-term establishment of subordinate status. Overall, these findings highlight a role for the oxytocinergic system in the mechanisms by which stress facilitates the long-term establishment of social hierarchy (Timmer et al., 2011).

A large body of research has emphasized a role for glucocorticoids-essential hormones of the activated hypothalamuspituitary-adrenocortical (HPA) axis-in the enhancement of memory consolidation of emotionally arousing experiences (de Kloet et al., 1999, 2005; de Kloet, 2000; Joëls, 2006; Roozendaal, 2000; Sandi and Pinelo-Nava, 2007; de Quervain et al., 2009). This research and the previously observed effects of stress in the dominance hierarchy paradigm (Cordero and Sandi, 2007) supported the investigation of the mediating action of glucocorticoids in the long-term establishment of social rank memory. Timmer and Sandi (2010) showed that when corticosterone is injected into the dominant (but not submissive) animal after (but not before) the first social encounter, a long-term maintenance of the hierarchy is observed 1 week later. This corticosterone effect mimics previously reported actions of stress in the same model and therefore implicates glucocorticoids in the consolidation of memory for a recently established hierarchy. Importantly, other studies have shown that once a hierarchy has been established, corticosterone does not appear to affect aggressive behavior in the colony, suggesting that the initial establishment of a hierarchy, but not the stability of a previously well-established hierarchy, might be particularly sensitive to modulation by glucocorticoids (Mikics et al., 2007).

\subsection{Stress effects in social recognition}

In the social recognition task, the effects of stress on social recognition were studied in female rats that were evaluated for their ability to recognize a juvenile. As previously noted, rats show poor memory in this paradigm, as memory declines as early as $2 \mathrm{~h}$ after initial exposure to the unfamiliar subject. However, when stress was applied to adult female rats (in the form of social defeat as a result of their interaction with an aggressive male) before their first contact with the juvenile rat, these female rats showed high social recognition levels when tested $2 \mathrm{~h}$ after the interaction with the juvenile rat (Penka et al., 2004). The stress neuropeptide corticotropin-releasing factor (CRF) has been implicated in this phenomenon because, using the same experimental paradigm in females, forgetting at the 2 -h delay was reversed by the administration of a $1-\mu \mathrm{g}$ dose of the CRF binding protein ligand inhibitor, rat/human CRF (peptide sequences 6-33). Conversely, administration of a competitive CRF receptor antagonist $[0.2,1$ or $5 \mu \mathrm{g}$ ICV doses of D-Phe CRF (peptide sequences 12-41)] $15 \mathrm{~min}$ prior to the first juvenile exposure dose-dependently impaired learning performance with a 30-min delay. The effective dose was the lower dose used $(0.2 \mu \mathrm{g})$, which impaired performance in the memory test without affecting social investigation during the first juvenile exposure. In contrast, the higher doses suppressed social investigation during the first encounter and were thus not suited for this type of study (Heinrichs, 2003).

Social recognition memory has also been shown to be affected by early life stress. Wistar rats were separated from their dams for $3 \mathrm{~h}$ per day during the first 2 weeks of life, and the males were tested at adulthood (16-week-old). The rats that were subjected to maternal separation displayed a failure to discriminate between a previously encountered rat and a novel rat after a 60-min delay (Lukas et al., 2011). This social recognition impairment was accompanied by a failure of AVP to show increased release within the lateral septum, which is characteristically observed during social memory acquisition in adult control rats (Lukas et al., 2011). Interestingly, a normal septal AVP response was observed in these maternally separated rats when stress was of a non-social nature, such as exposure to forced swimming, suggesting that the blunted response observed was social stimulus-specific. Importantly, AVP administered into the lateral septum during social memory acquisition could restore social recognition with a 60-min delay in adult rats that previously experienced maternal separation. Therefore, early life stress seems to induce long-term effects in social memory pathways-the septal AVP system in particular-resulting in a decreased capacity to form new social memories.

In another recent study, rats were subjected to maternal separation (MS) for $3 \mathrm{~h}$ /day during the first 2 postnatal weeks and tested in the social recognition test with only a 5-min intertrial delay (Hulshof et al., 2011). Neither MS-treated nor control animals showed a preference for the novel conspecific vs. a familiar one. However, rats that received additional stress (prior foot-shock in MS and control rats) did show a behavior indicative of social recognition (Hulshof et al., 2011).

The CRF system has also been implicated in early life changes in stress pathways and social memory. Transgenic mice with early postnatal onset of CRF overexpression (CRF-OE) exhibited improved long-term social recognition, whereas short-term social recognition (10 min) was not affected (Kasahara et al., 2011). It should be noted that CRF-OE mice already showed enhanced social investigation during the first encounter, which suggests that this system increases the mouse's motivation to engage in social interactions.

\section{Conclusions}

Since the early pharmacological studies during the 1980s that identified the social neuropeptides as key regulators of social behaviors and social memories (Dantzer et al., 1987), this field has steadily expanded, and recently, there has been an explosion of interest. The use of complementary experimental approaches for understanding the neurobiology of social recognition and social learning has allowed progressive mapping of brain regions and of the neurochemical messengers underlying these special types of memory. Studies with a focus on the neurobiology of social recognition and social memories in particular have identified the social neuropeptides OT and AVP, along with the involvement and modulatory role of several neurotransmitter systems, and the OB, MeA and LS as critically important for the coding of this type of memory. Conversely, the more conclusive data to date regarding the mechanisms underlying social learning or learning from others highlight the hippocampus and the cholinergic projections to both the hippocampus and the neocortex as critically important for different phases (e.g., learning and retrieval) of social learning. 
The emerging interest in understanding the influences that modulate the formation of these types of memories has meant that stress and the central (CRF) and peripheral (glucocorticoids) stress systems have now been identified as important modulators of social memory formation. Strikingly, stress seems to affect social memories by regulating the same neuropeptide systems that are essential to the transduction and encoding of social information. These recent findings open a new and intriguing research area by underscoring that stress is an important regulator of the social brain.

\section{Acknowledgements}

The authors would like to thank current and previous lab members, M. Isabel Cordero and M. Timmer, for their original contributions to the reported work. This work was supported by grants from the Swiss National Science Foundation (31003AB-135710; Sinergia CRSIK0-122697 and CRSIK0-122691), the Swiss Network for International Studies, and by intramural funding from the Ecole Polytechnique Federale de Lausanne (EPFL).

\section{References}

Argyriou, A., Prast, H., Philippu, A., 1998. Melatonin facilitates short-term memory. Eur. J. Pharmacol. 349, 159-162.

Bannerman, D.M., Lemaire, M., Beggs, S., Rawlins, J.N., Iversen, S.D., 2001. Cytotoxic lesions of the hippocampus increase social investigation but do not impair social-recognition memory. Exp. Brain Res. 138, 100-109.

Bannerman, D.M., Lemaire, M., Yee, B.K., Iversen, S.D., Oswald, C.J., Good, M.A., Rawlins, J.N., 2002. Selective cytotoxic lesions of the retrohippocampal region produce a mild deficit in social recognition memory. Exp. Brain Res. 142 , 395-401.

Benelli, A., Bertolini, A., Poggioli, R., Menozzi, B., Basaglia, R., Arletti, R., 1995. Polymodal dose-response curve for oxytocin in the social recognition test. Neuropeptides 28, 251-255.

Berger-Sweeney, J., Stearns, N.A., Frick, K.M., Beard, B., Baxter, M.G., 2000. Cholinergic basal forebrain is critical for social transmission of food preferences. Hippocampus 10, 729-738.

Bertaina, V., Destrade, C., 1995. Differential time courses of c-Fos mRNA expression in hippocampal subfields following acquisition and recall testing in mice. Brain Res. Cogn. Brain Res. 2, 269-275.

Bielsky, I.F., Young, L.J., 2004. Oxytocin, vasopressin, and social recognition in mammals. Peptides 25, 1565-1574.

Bielsky, I.F., Hu, S.B., Szegda, K.L., Westphal, H., Young, L.J., 2004. Profound impairment in social recognition and reduction in anxiety-like behavior in vasopressin V1a receptor knockout mice. Neuropsychopharmacology 29, 483-493.

Bielsky, I.F., Hu, S.B., Ren, X., Terwilliger, E.F., Young, L.J., 2005. The V1a vasopressin receptor is necessary and sufficient for normal social recognition: a gene replacement study. Neuron 47, 503-513.

Blanchard, R.J., Flanelly, K.J., Blanchard, D.C., 1988. Life-span studies of dominance and aggression in established colonies of laboratory rats. Physiol. Behav. 43, 1-7.

Bluthé, R.M., Dantzer, R., 1992. Chronic intracerebral infusions of vasopressin and vasopressin antagonist modulate social recognition in rat. Brain Res. $572,261-264$.

Bluthé, R.M., Gheusi, G., Dantzer, R., 1993. Gonadal steroids influence the involvement of arginine vasopressin in social recognition in mice. Psychoneuroendocrinology $18,323-335$.

Boix-Trelis, N., Vale-Martínez, A., Guillazo-Blanch, G., Costa-Miserachs, D., Martí-Nicolovius, M., 2006. Effects of nucleus basalis magnocellularis stimulation on a socially transmitted food preference and c-Fos expression. Learn. Mem. 13, 783-793.

Boix-Trelis, N., Vale-Martínez, A., Guillazo-Blanch, G., Martí-Nicolovius, M., 2007. Muscarinic cholinergic receptor blockade in the rat prelimbic cortex impairs the social transmission of food preference. Neurobiol. Learn. Mem. 87, 659-668.

Brightwell, J.J., Smith, C.A., Countryman, R.A., Neve, R.L., Colombo, P.J., 2005. Hippocampal overexpression of mutant CREB blocks long-term, but not short-term memory for a socially transmitted food preference. Learn. Mem. 12, 12-17.

Bunsey, M., Eichenbaum, H., 1995. Selective damage to the hippocampal region blocks long-term retention of a natural and nonspatial stimulus-stimulus association. Hippocampus 5, 546-556.

Burton, S., Murphy, D., Qureshi, U., Sutton, P., O’Keefe, J., 2000. Combined lesions of hippocampus and subiculum do not produce deficits in a nonspatial social olfactory memory task. J. Neurosci. 20, 5468-5475.

Carballo-Márquez, A., Vale-Martínez, A., Guillazo-Blanch, G., Torras-Garcia, M., Boix-Trelis, N., Martí-Nicolovius, M., 2007. Differential effects of muscarinic receptor blockade in prelimbic cortex on acquisition and memory formation of an odor-reward task. Learn. Mem. 14, 616-624.

Carballo-Márquez, A., Vale-Martínez, A., Guillazo-Blanch, G., Martí-Nicolovius, M., 2009a. Muscarinic receptor blockade in ventral hippocampus and prelimbic cortex impairs memory for socially transmitted food preference. Hippocampus 19, 446-455

Carballo-Márquez, A., Vale-Martínez, A., Guillazo-Blanch, G., Marti-Nicolovius, M. 2009b. Muscarinic transmission in the basolateral amygdala is necessary for the acquisition of socially transmitted food preferences in rats. Neurobiol. Learn. Mem. 91, 98-101.

Castel, M., Morris, J.F., 1988. The neurophysin-containing innervation of the forebrain of the mouse. Neuroscience 24, 937-966.

Choleris, E., Clipperton-Allen, A.E., Gray, D.G., Diaz-Gonzalez, S., Welsman, R.G., 2011. Differential effects of dopamine receptor D1-type and D2-type antagonists and phase of estrous cycle on social learning of food preferences, feeding, and social interactions in mice. Neuropsychopharmacology 36, 1689-1702.

Choleris, E., Gustafsson, J.A., Korach, K.S., Muglia, L.J., Pfaff, D.W., Ogawa, S., 2003. An estrogen-dependent four-gene micronet regulating social recognition: a study with oxytocin and estrogen receptor-alpha and -beta knockout mice. Proc. Natl. Acad. Sci. U.S.A. 100, 6192-6197.

Choleris, E., Little, S.R., Mong, J.A., Puram, S.V., Langer, R., Pfaff, D.W., 2007 Microparticle-based delivery of oxytocin receptor antisense DNA in the medial amygdala blocks social recognition in female mice. Proc. Natl. Acad. Sci. U.S.A. 104, 4670-4675.

Choleris, E., Clipperton-Allen, A.E., Phan, A., Kavaliers, M., 2009. Neuroendocrinology of social information processing in rats and mice. Front. Neuroendocrinol. 30, 442-459.

Clark, R.E., Broadbent, N.J., Zola, S.M., Squire, L.R., 2002. Anterograde amnesia and temporally graded retrograde amnesia for a nonspatial memory task after lesions of hippocampus and subiculum. J. Neurosci. 22, 4663-4669.

Clipperton, A.E., Spinato, J.M., Chernets, C., Pfaff, D.W., Choleris, E., 2008. Differential effects of estrogen receptor alpha and beta specific agonists on social learning of food preferences in female mice. Neuropsychopharmacology 33, 2362-2375.

Cordero, M.I., Sandi, C., 2007. Stress amplifies memory for social hierarchy. Front. Neurosci. 1, 175-184.

Countryman, R.A., Gold, P.E., 2007. Rapid forgetting of social transmission of food preferences in aged rats: relationship to hippocampal CREB activation. Learn. Mem. 14, 350-358.

Countryman, R.A., Kaban, N.L., Colombo, P.J., 2005. Hippocampal c-Fos is necessary for long-term memory of a socially transmitted food preference. Neurobiol. Learn. Mem. 84, 175-183.

Crawley, J.N., Chen, T., Puri, A., Washburn, R., Sullivan, T.L., Hill, J.M., Young, N.B., Nadler, J.J., Moy, S.S., Young, L.J., Caldwell, H.K., Young, W.S., 2007. Social approach behaviors in oxytocin knockout mice: comparison of two independent lines tested in different laboratory environments. Neuropeptides 41, 145-163.

Dantzer, R., Bluthe, R.M., Koob, G.F., Le Moal, M., 1987. Modulation of social memory in male rats by neurohypophyseal peptides. Psychopharmacology (Berl.) 91, 363-368

de Kloet, E.R., 2000. Stress in the brain. Eur. J. Pharmacol. 405, 187-198.

de Kloet, E.R., Oitzl, M.S., Joëls, M., 1999. Stress and cognition: are corticosteroids good or bad guys? Trends Neurosci. 22, 422-426.

de Kloet, E.R., Joëls, M., Holsboer, F., 2005. Stress and the brain: from adaptation to disease. Nat. Rev. Neurosci. 6, 463-475.

de Quervain, D.J., Aerni, A., Schelling, G., Roozendaal, B., 2009. Glucocorticoids and the regulation of memory in health and disease. Front. Neuroendocrinol. 30, 358-370.

DeVito, L.M., Konigsberg, R., Lykken, C., Sauvage, M., Young 3rd, W.S., Eichenbaum, H. 2009. Vasopressin 1b receptor knock-out impairs memory for temporal order. J. Neurosci. 29, 2676-2683.

Di Cara, B., Panayi, F., Gobert, A., Dekeyne, A., Sicard, D., De Groote, L. Millan, M.J., 2007. Activation of dopamine D1 receptors enhances cholinergic transmission and social cognition: a parallel dialysis and behavioural study in rats. Int. J. Neuropsychopharmacol. 10, 383-399.

Dluzen, D.E., Muraoka, S., Engelmann, M. Landgraf, R, 1998. The effects of infusion of arginine vasopressin, oxytocin, or their antagonists into the olfactory bulb upon social recognition responses in male rats. Peptides 19, 999-1005.

Donaldson, Z.R., Young, L.J., 2008. Oxytocin, vasopressin, and the neurogenetics of sociality. Science 322, 900-904.

Ebner, K., Wotjak, C.T., Landgraf, R., Engelmann, M., 2000. A single social defeat experience selectively stimulates the release of oxytocin, but not vasopressin, within the septal brain area of male rats. Brain Res. 872, 87-92.

Egashira, N., Tanoue, A., Matsuda, T., Koushi, E., Harada, S., Takano, Y., Tsujimoto, G., Mishima, K., Iwasaki, K., Fujiwara, M., 2007. Impaired social interaction and reduced anxiety-like behavior in vasopressin V1a receptor knockout mice. Behav. Brain Res. 178, 123-127.

Engelmann, M., 2009. Competition between two memory traces for long-term recog nition memory. Neurobiol. Learn. Mem. 91, 58-65.

Engelmann, M., Landgraf, R., 1994. Microdialysis administration of vasopressin into the septum improves social recognition in Brattleboro rats. Physiol. Behav. $55,145-149$

Engelmann, M., Wotjak, C.T., Landgraf, R., 1995. Social discrimination procedure: an alternative method to investigate juvenile recognition abilities in rats. Physiol. Behav. 58, 315-321.

Engelmann, M., Ebner, K., Landgraf, R., Holsboer, F., Wotjak, C.T., 1999. Emotional stress triggers intrahypothalamic but not peripheral release of oxytocin in male rats. J. Neuroendocrinol. 11, 867-872.

Engelmann, M., Hädicke, J., Noack, J., 2011. Testing declarative memory in laboratory rats and mice using nonconditional social discrimination procedure. Nat. Protoc. $6,1152-1162$. 
Feifel, D., Mexal, S., Melendez, G., Liu, P.Y., Goldenberg, J.R., Shilling, P.D., 2009. The brattleboro rat displays a natural deficit in social discrimination that is restored by clozapine and a neurotensin analog. Neuropsychopharmacology 34, 2011-2018.

Ferguson, J.N., Young, L.J., Hearn, E.F., Matzuk, M.M., Insel, T.R., Winslow, J.T., 2000 Social amnesia in mice lacking the oxytocin gene. Nat. Genet. 25, 284-288.

Ferguson, J.N., Aldag, J.M., Insel, T.R., Young, L.J., 2001. Oxytocin in the medial amygdala is essential for social recognition in the mouse. J. Neurosci. 21, 8278-8285.

Ferguson, J.N., Young, L.J., Insel, T.R., 2002. The neuroendocrine basis of social recognition. Front. Neuroendocrinol. 23, 200-224.

Galef, B.G., 1985. Direct and indirect behavioral pathways to the social transmission of food avoidance. Ann. N. Y. Acad. Sci. 443, 203-215.

Galef, B.G., Kennett, D.J., 1987. Different mechanisms for social transmission of diet preference in rat pups of different ages. Dev. Psychobiol. 20, 209-215.

GalefJr., B.G., Mason, J.R., Preti, G., Bean, N.J., 1988. Carbon disulfide: a semiochemical meditating socially induced diet choice in rats. Physiol. Behav. 42, 119-124.

Galef Jr, B.G., Whiskin, E.E., 2003. Socially transmitted food preferences can be used to study long-term memory in rats. Learn. Behav. 31, 160-164.

Galef, B.G., Wigmore, S.W., 1983. Transfer of information concerning distant foods: a laboratory investigation of the 'information-centre' hypothesis. Anim. Behav. 31, 748-758.

Griffin, M.G., Taylor, G.T., 1995. Norepinephrine modulation of social memory: evidence for a time-dependent functional recovery of behavior. Behav. Neurosci. 109, 466-473.

Guzowski, J.F., Setlow, B., Wagner, E.K., McGaugh, J.L., 2001. Experience-dependent gene expression in the rat hippocampus after spatial learning: a comparison of the immediate-early genes Arc, c-Fos, and zif268. J. Neurosci. $21,5089-5098$.

Heinrichs, S.C., 2003. Modulation of social learning in rats by brain corticotropinreleasing factor. Brain Res. 994, 107-114

Hernando, F., Schoots, O., Lolait, S.J., Burbach, J.P., 2001. Immunohistochemical localization of the vasopressin V1b receptor in the rat brain and pituitary gland: anatomical support for its involvement in the central effects of vasopressin. Endocrinology 142, 1659-1668.

Holmes, A., Wren, C.C., Harris, A.P., Thayer, K.E., Crawley, J.N., 2002. Behavioral profiles of inbred strains on novel olfactory, spatial and emotional tests for reference memory in mice. Genes, Brain Behav. 1, 55-69.

Hulshof, H.J., Novati, A., Sgoifo, A., Luiten, P.G., den Boer, J.A., Meerlo, P., 2011. Maternal separation decreases adult hippocampal cell proliferation and impairs cognitive performance but has little effect on stress sensitivity and anxiety in adult Wistar rats. Behav. Brain Res. 216, 552-560.

Joëls, M., 2006. Corticosteroid effects in the brain: U-shape it. Trends Pharmacol. Sci 27, 244-250.

Kasahara, M., Groenink, L., Kas, M.J., Bijlsma, E.Y., Olivier, B., Sarnyai, Z., 2011. Influence of transgenic corticotropin-releasing factor (CRF) over-expression on social recognition memory in mice. Behav. Brain Res. 218, 357-362.

Kim, J.J., Diamond, D.M., 2002. The stressed hippocampus, synaptic plasticity and lost memories. Nat. Rev. Neurosci. 3, 453-462.

Klinkenberg, I., Blokland, A., 2010. The validity of scopolamine as a pharmacological model for cognitive impairment: a review of animal behavioral studies. Neurosci. Biobehav. Rev. 34, 1307-1350.

Kogan, J.H., Frankland, P.W., Silva, A.J., 2000. Long-term memory underlying hippocampus-dependent social recognition in mice. Hippocampus 10, 47-56.

Landgraf, R., Wotjak, C.T., Neumann, I.D., Engelmann, M., 1998. Release of vasopressin within the brain contributes to neuroendocrine and behavioral regulation. Prog. Brain Res. 119, 201-220.

Landgraf, R., Frank, E., Aldag, J.M., Neumann, I.D., Sharer, C.A., Ren, X., Terwilliger, E.F. Niwa, M., Wigger, A., Young, L.J., 2003. Viral vector-mediated gene transfer of the vole V1a vasopressin receptor in the rat septum: improved social discrimination and active social behaviour. Eur. J. Neurosci. 18, 403-411.

Lee, H.J., Caldwell, H.K., Macbeth, A.H., Tolu, S.G., Young 3rd, W.S., 2008. A conditional knockout mouse line of the oxytocin receptor. Endocrinology 149 3256-3263.

Letty, S., Child, R., Dumuis, A., Pantaloni, A., Bockaert, J., Rondouin, G., 1997. 5HT4 receptors improve social olfactory memory in the rat. Neuropharmacology 36, 681-687.

Lim, M.M., Wang, Z., Olazábal, D.E., Ren, X., Terwilliger, E.F., Young, LJ, 2004. Enhanced partner preference in a promiscuous species by manipulating the expression of a single gene. Nature $429,754-757$.

Loiseau, F., Dekeyne, A., Millan, M.J., 2008. Pro-cognitive effects of 5-HT6 recepto antagonists in the social recognition procedure in rats: implication of the frontal cortex. Psychopharmacology (Berl.) 196, 93-104.

Lukas, M., Bredewold, R., Landgraf, R., Neumann, I.D., Veenema, A.H., 2011. Early life stress impairs social recognition due to a blunted response of vasopressin release within the septum of adult male rats. Psychoneuroendocrinology $36,843-853$

Luksys, G., Sandi, C., 2011. Neural mechanisms and computations underlying stress effects on learning and memory. Curr. Opin. Neurobiol. 21, 502-508.

Maaswinkel, H., Baars, A.M., Gispen, W.H., Spruijt, B.M., 1996. Roles of the basolateral amygdala and hippocampus in social recognition in rats. Physiol. Behav. $60,55-63$.

Marino, M.D., Bourdélat-Parks, B.N., Cameron Liles, L., Weinshenker, D., 2005. Genetic reduction of noradrenergic function alters social memory and reduces aggression in mice. Behav. Brain Res. 161, 197-203.

Markham, J.A., Juraska, J.M., 2007. Social recognition memory: influence of age, sex, and ovarian hormonal status. Physiol. Behav. 92, 881-888
McGaugh, J.L., Roozendaal, B., 2002. Role of adrenal stress hormones in forming lasting memories in the brain. Curr. Opin. Neurobiol. 12, 205-210.

Meyer-Lindenberg, A., 2008. Impact of prosocial neuropeptides on human brain function. Prog. Brain Res. 170, 463-470.

Mikics, E., Barsy, B., Haller, J., 2007. The effects of glucocorticoids on aggressiveness in established colonies of rats. Psychoneuroendocrinology 32, 160-170.

Millan, M.J., Di Cara, B., Dekeyne, A., Panayi, F., De Groote, L., Sicard, D. Cistarelli, L., Billiras, R., Gobert, A., 2007. Selective blockade of dopamine D(3) versus $\mathrm{D}(2)$ receptors enhances frontocortical cholinergic transmission and social memory in rats: a parallel neurochemical and behavioural analysis. J. Neurochem. 100, 1047-1061.

Neumann, I.D., 2007. Stimuli and consequences of dendritic release of oxytocin within the brain. Biochem. Soc. Trans. 35, 1252-1257.

Noack, J., Richter, K., Laube, G., Haghgoo, H.A., Veh, R.W., Engelmann, M., 2010. Different importance of the volatile and non-volatile fractions of an olfactory signature for individual social recognition in rats versus mice and short-term versus long-term memory. Neurobiol. Learn. Mem. 94, 568-575.

Penka, L.L., Bond, T.L., Heinrichs, S.C., 2004. Non-specific effect of fear conditioning and specific effect of social defeat on social recognition memory performance in female rats. Stress 7, 63-72.

Popik, P., van Ree, J.M., 1993. Social transmission of a flavored tea preferences: facilitation by a vasopressin analog and oxytocin. Behav. Neural Biol. 59, 63-68.

Popik, P., van Ree, J.M., 1998. Neurohypophyseal peptides and social recognition in rats. Prog. Brain Res. 119, 415-436.

Prast, H., Argyriou, A., Phillipu, A., 1996. Histaminergic neurons facilitate social memory in rats. Brain Res. 734, 316-318.

Prediger, R.D., De-Mello, N., Takahashi, R.N., 2006. Pilocarpine improves olfactory discrimination and social recognition memory deficits in 24-month-old rats. Eur. J. Pharmacol. 531, 176-182.

Reijmers, L.G., Leus, I.E., Burbach, J.P., Spruijt, B.M., van Ree, J.M., 2001a. Social memory in the rat: circadian variation and effect of circadian rhythm disruption. Physiol. Behav. 72, 305-309.

Reijmers, L.G., Hoekstra, K., Burbach, J.P., van Ree, J.M., Spruijt, B.M., 2001b. Long term impairment of social memory in the rat after social defeat is not restored by desglycinamide-vasopressin. Neurosci. Lett. 305, 145-148.

Richter, K., Wolf, G., Engelmann, M., 2005. Social recognition memory requires two stages of protein synthesis in mice. Learn. Mem. 12, 407-413.

Roberts, M., Shapiro, M., 2002. NMDA receptor antagonists impair memory for nonspatial, socially transmitted food preference. Behav. Neurosci. $116,1059-1069$.

Roozendaal, B., 2000. 1999 Curt P. Richter award. Glucocorticoids and the regulation of memory consolidation. Psychoneuroendocrinology 25, 213-238.

Ross, R.S., Eichenbaum, H., 2006. Dynamics of hippocampal and cortical activation during consolidation of a nonspatial memory. J. Neurosci. 26, 4852-4859.

Ross, H.E., Young, L.J., 2009. Oxytocin and the neural mechanisms regulating socia cognition and affiliative behavior. Front. Neuroendocrinol. 30, 534-547.

Ross, R.S., McGaughy, J., Eichenbaum, H., 2005. Acetylcholine in the orbitofrontal cortex is necessary for the acquisition of a socially transmitted food preference. Learn. Mem. 12, 302-306.

Rudebeck, P.H., Walton, M.E., Millette, B.H., Shirley, E., Rushworth, M.F., Bannerman, D.M., 2007. Distinct contributions of frontal areas to emotion and social behaviour in the rat. Eur. J. Neurosci. 26, 2315-2326.

Samuelsen, C.L., Meredith, M., 2011. Oxytocin antagonist disrupts male mouse medial amygdala response to chemical-communication signals. Neuroscience 180, 96-104.

Sandi, C., 2004. Stress, cognitive impairment and cell adhesion molecules. Nat. Rev. Neurosci. 5, 917-930.

Sandi, C., Pinelo-Nava, M.T., 2007. Stress and memory: behavioral effects and neurobiological mechanisms. Neural Plast. 2007, 78970.

Sekiguchi, R., Wolterink, G., van Ree, J.M., 1991. Analysis of the influence of vasopressin neuropeptides on social recognition of rats. Eur. Neuropsychopharmacol. 1, 123-126.

Shettleworth, S.J., 1998. Cognition, Evolution and Behavior. Oxford University Press, New York, pp. 425-474.

Shires, K.L., Aggleton, J.P., 2008. Mapping immediate-early gene activity in the rat after place learning in a water-maze: the importance of matched control conditions. Eur. J. Neurosci. 28, 982-996.

Silverman, J.L., Yang, M., Lord, C., Crawley, J.N., 2010. Behavioural phenotyping assays for mouse models of autism. Nat. Rev. Neurosci. 11, 490-502.

Smith, C.A., Countryman, R.A., Sahuque, L.L., Colombo, P.J., 2007. Time-courses of Fos expression in rat hippocampus and neocortex following acquisition and recall of a socially transmitted food preference. Neurobiol. Learn. Mem. 88, 65-74.

Smith, C.A., East, B.S., Colombo, P.J., 2010. The orbitofrontal cortex is not necessary for acquisition or remote recall of socially transmitted food preferences. Behav. Brain Res. 208, 243-249.

Smit-Rigter, L.A., Wadman, W.J., van Hooft, J.A., 2010. Impaired social behavior in 5-HT3a receptor knockout mice. Front. Behav. Neurosci. 4, 169.

Spiteri, T., Musatov, S., Ogawa, S., Ribeiro, A., Pfaff, D.W., Agmo, A., 2010. The role of the estrogen receptor alpha in the medial amygdala and ventromedial nucleus of the hypothalamus in social recognition, anxiety and aggression. Behav. Brain Res. 210, 211-220.

Squires, A.S., Peddle, R., Milway, S.J., Harley, C.W., 2006. Cytotoxic lesions of the hippocampus do not impair social recognition memory in socially housed rats. Neurobiol. Learn. Mem. 85, 95-101.

Strupp, B.J., Bunsey, M., Bertsche, B., Levitsky, D.A., Kesler, M., 1990. Enhancement and impairment of memory retrieval by a vasopressin metabolite: 
an interaction with the accessibility of the memory. Behav. Neurosci. 104, 268-276.

Takanayagi, Y., Yoshida, M., Bielsky, I.F., Ross, H.E., Kawamata, M., Onaka, T., Yanagisawa, T., Kimura, T., Matzuk, M.M., Young, L.J., Nishimori, K., 2005. Pervasive social deficits, but normal parturition, in oxytocin receptor-deficient mice. Proc. Natl. Acad. Sci. U.S.A. 102, 16096-16101.

Tang, A.C., Nakazawa, M., Romeo, R.D., Reeb, B.C., Sisti, H., McEwen, B.S., 2005. Effects of long-term estrogen replacement on social investigation and social memory in ovariectomized C57BL/6 mice. Horm. Behav. 47, 350-357.

Terranova, J.P., Pério, A., Worms, P., Le Fur, G., Soubrié, P., 1994. Social olfactory recognition in rodents: deterioration with age, cerebral ischaemia and septal lesion. Behav. Pharmacol. 5, 90-98.

Thor, D.H., Hollaway, W.R., 1982. Social memory of the male laboratory rat. J. Comp. Physiol. Psychol. 96, 1000-1006.

Timmer, M., Sandi, C., 2010. A role for glucocorticoids in the long-term establishment of a social hierarchy. Psychoneuroendocrinology 35, 1543-1552.

Timmer, M., Cordero, M.I., Sevelinges, Y., Sandi, C., 2011. Evidence for a role of oxytocin and vasopressin 1 a receptors in the long-term establishment of dominance hierarchies. Neuropsychopharmacology 36, 2349-2356.

Tobin, V.A., Hashimoto, H., Wacker, D.W., Takayanagi, Y., Langnaese, K. Caquineau, C., Noack, J., Landgraf, R., Onaka, T., Leng, G., Meddle, S.L., Engelmann, M., Ludwig, M., 2010. An intrinsic vasopressin system in the olfactory bulb is involved in social recognition. Nature 464, 413-417.

Vale-Martínez, A., Baxter, M.G., Eichenbaum, H., 2002. Selective lesions of basal forebrain cholinergic neurons produce anterograde and retrograde deficits in a social transmission of food preference task in rats. Eur. J. Neurosci. 16, 983-998.

Valsecchi, P., Galef Jr., B.G., 1989. Social influences on food preferences of house mice (Mus musculus). Int. J. Comp. Psychol. 2, 245-256.

van der Kooij, M.A., Nijboer, C.H., Ohl, F., Groenendaal, F., Heijnen, C.J., van Bel, F., Kavelaars, A., 2010a. NF-kappaB inhibition after neonatal cerebral hypoxia-ischemia improves long-term motor and cognitive outcome in rats. Neurobiol. Dis. 38, 266-272.

van der Kooij, M.A., Ohl, F., Arndt, S.S., Kavelaars, A., van Bel, F., Heijnen, C.J., 2010b. Mild neonatal hypoxia-ischemia induces long-term motor- and cognitive impairments in mice. Brain Behav. Immun. 24, 850-856.
Vann, S.D., Brown, M.W., Erichsen, J.T., Aggleton, J.P., 2000. Fos imaging reveals differential patterns of hippocampal and parahippocampal subfield activation in rats in response to different spatial memory tests. J. Neurosci. 20, 2711-2718.

Wang, Y., Fontanini, A., Katz, D.B., 2006. Temporary basolateral amygdala lesions disrupt acquisition of socially transmitted food preferences in rats. Learn. Mem. $13,794-800$

Wanisch, K., Wotjak, C.T., Engelmann, M., 2008. Long-lasting second stage of recognition memory consolidation in mice. Behav. Brain Res. 186, 191-196.

Wenk, G.L., 1997. The nucleus basalis magnocellularis cholinergic system: one hundred years of progress. Neurobiol. Learn. Mem. 67, 85-95.

Wersinger, S.R., Caldwell, H.K., Martinez, L., Gold, P., Hu, S.B., Young 3rd, W.S., 2007. Vasopressin 1 a receptor knockout mice have a subtle olfactory deficit but norma aggression. Genes Brain Behav. 6, 540-551.

Winocur, G., Moscovitsch, M., 1999. Anterograde and retrograde amnesia after lesions to frontal cortex in rats. J. Neurosci. 19, 9611-9617.

Winslow, J.T., 2003. Mouse social recognition and preference. Curr. Protoc. Neurosci. Chapter 8:Unit 8.16.

Winslow, J.T., Insel, T.R., 2004. Neuroendocrine basis of social recognition. Curr. Opin. Neurobiol. 14, 248-253.

Wotjak, C.T., Kubota, M., Liebsch, G., Montkowski, A., Holsboer, F., Neumann, I., Landgraf, R., 1996. Release of vasopressin within the rat paraventricular nucleus in response to emotional stress: a novel mechanism of regulating adrenocorticotropic hormone secretion? J. Neurosci. 16, 7725-7732.

Wotjak, C.T., Ganster, J., Kohl, G., Holsboer, F., Landgraf, R., Engelmann, M., 1998 Dissociated central and peripheral release of vasopressin, but not oxytocin, in response to repeated swim stress: new insights into the secretory capacities of peptidergic neurons. Neuroscience 85, 1209-1222.

Wrenn, C.C., 2004. Social transmission of food preference in mice. Curr. Protoc Neurosci., Chapter 8:Unit 8.5G.

Young, L.J., Wang, Z., 2004. The neurobiology of pair bonding. Nat. Neurosci. 7, 1048-1054.

Young, L.J., Wang, Z., Insel, T.R., 1998. Neuroendocrine bases of monogamy. Trends Neurosci. 21, 71-75.

Young, L.J., Nilsen, R., Waymire, K.G., MacGregor, G.R., Insel, T.R., 1999. Increased affiliative response to vasopressin in mice expressing the V1a receptor from a monogamous vole. Nature 400, 766-768. 